
\title{
28 Research Soure \\ Right-Side Spatial Neglect And White Matter Disconnection After Left Hemisphere Strokes
}

Monica Toba ( $\square$ monica.n.toba@gmail.com )

University of Picardy Jules Verne Faculty of Medicine: Universite de Picardie Jules Verne UFR de Medecine https://orcid.org/0000-0002-4503-2271

Rafaella Migliaccio

Hospital Pitie-Salpetriere: Hopital Universitaire Pitie Salpetriere

Pascale Pradat Diehl

Hospital Pitie-Salpetriere: Hopital Universitaire Pitie Salpetriere

\section{Paolo Bartolomeo}

Hospital Pitie-Salpetriere: Hopital Universitaire Pitie Salpetriere

\section{Research Article}

Keywords: right neglect, attention, disconnection, white matter, stroke

Posted Date: March 3rd, 2022

DOI: https://doi.org/10.21203/rs.3.rs-1352744/v1

License: (1) (1) This work is licensed under a Creative Commons Attribution 4.0 International License. Read Full License 


\section{Abstract}

Spatial neglect usually concerns left-sided events after right hemisphere damage. Its anatomical correlates are debated, with evidence suggesting an important role for fronto-parietal white matter disconnections in the right hemisphere. Here we describe the less frequent occurrence of neglect for rightsided events, observed in three right-handed patients after a focal stroke in the left hemisphere. Patients were tested one month and three months after stroke. They performed a standardised paper-and-pencil neglect battery and underwent brain MRI with both structural and Diffusion Tensor (DT) sequences, in order to assess both grey matter and white matter tracts metrics. Lesions were manually reconstructed for each patient. Patients presented signs of mild right-sided neglect during visual search and line bisection, as well as pathological performance in real-life situations. Structural MRI demonstrated left parietal strokes in two patients, in the region extending from the postcentral gyrus to the temporo-parietal junction. One of these two patients also had had a previous occipital stroke. The remaining patient had a left frontal stroke, affecting the precentral, the postcentral gyri and the basal ganglia. DT MRI tractography showed disconnections in the fronto-parietal regions, concerning principally the superior longitudinal fasciculus (SLF). These results suggest an important role for left SLF disconnection in rightside neglect, which complements analogous evidence for right SLF disconnection in left-side neglect.

\section{Introduction}

Spatial neglect typically affects left-sided events after right hemisphere damage, with clinical signs such as a "magnetic attraction" of gaze to right-sided stimuli (Gainotti, D'Erme, \& Bartolomeo, 1991; Toba, Rabuffetti, et al., 2018) and neglect of left-sided items on visual search (Mark, Kooistra, \& Heilman, 1988). Patients' attention tends to be captured by right-sided objects and cannot easily disengage from them (Posner, Walker, Friedrich, \& Rafal, 1984; Rastelli, Funes, Lupiáñez, Duret, \& Bartolomeo, 2008).

Contralesional right neglect after left hemisphere damage is less frequently reported, but different studies describe it to range from 0 to $76 \%$ in the left brain-damaged population (Bowen, McKenna, \& Tallis, 1999). Beis et al. (2004) showed that, in equivalent right and left brain-damaged subacute patients' samples, when global performance (i.e., neglect signs on at least one test from the battery used) was considered, neglect was twice more frequent in right brain damage (85\%), comparing with left brain damage (43\%). This inconsistency in the reported frequency of right neglect is probably firstly explained by patients' selection bias, given that spatial disorders are documented less often in left brain-damaged patients who frequently present language impairments and have difficulties in understanding tests instructions (Bowen et al., 1999). Nonetheless, descriptions of right neglect cases after left hemisphere stroke, sometimes do not report aphasia signs, the explanation lying probably in a different hemisphere dominance (Cambier, Masson, Guillot, \& Robine, 1985; Fischer, Alexander, Gabriel, Gould, \& Milione, 1991), that is another potential bias in considering right neglect. The moment of testing with respect to the stroke onset is also an important variable to consider. For instance, neglect tested in the acute stage seems to have similar incidences on right and left brain-damaged patients (62\% left neglect and $72 \%$ right neglect) (Stone et al., 1991), whereas in the subacute stage, neglect affects only $33 \%$ of the left hemisphere stroke patients, but 
$75 \%$ of the right brain-damaged patients (Stone, Patel, Greenwood, \& Halligan, 1992). Lastly, the variability of tests used in assessing neglect (Bowen et al., 1999) and the lesion localization are also essential in quantitative studies comparing right to left neglect.

If quantitatively there is no current agreement concerning right neglect, qualitatively, right neglect deficits were reported to be transient and less severe, and the spatial asymmetries observed in these patients to be non-significant (Weintraub, Daffner, Ahern, Price, \& Mesulam, 1996). An analysis of performances obtained by right-neglect patients in a battery of paper-and-pencil tests for assessing neglect (Beis et al., 2004) showed weak correlations between results in different tests. The same analysis in left-neglect patients' results obtained when tested with a similar battery, showed strong correlations between all the tests (Azouvi et al., 2002). These differences seem to confirm results observed clinically, that right neglect after left brain damage is a phenomenon with less consistency. Nonetheless, severe and persistent right neglect was documented to occur in patients with bilateral lesions (Weintraub et al., 1996), as well as in patients with neurodegenerative conditions (Andrade et al., 2010; Bartolomeo et al., 1998).

Until now, only a few studies have been conducted on right-sided neglect after left brain damage. Earlier investigations suggested that right neglect would be associated with more anterior lesions in left hemisphere, whereas left neglect would be the result of more posterior right hemisphere lesions (Ogden, 1985). However, this statement has not been confirmed in later studies (Beis et al., 2004) that concluded that right neglect could also be produced by posterior left lesions. In a voxel-based lesion-symptom mapping (VLSM) study conducted in 121 acute left-brain damaged stroke patients, Beume et al. (2017) reported patterns of neglect partly mirroring critical regions of the right hemisphere known to be associated with neglect, including the temporal gyrus, temporal pole, frontal operculum, and insula. Malherbe et al. (2018) analyzed causal functional contributions of grey and white matter regions in the same cohort of Beume et al. (2017) and emphasized the contributions of the temporal gyrus and inferior parietal lobe in the contralesional attentional bias. These findings have been confirmed in another study trying to disentangle between lesional patterns specific to neglect and extinction in right brain damaged patients (Beume et al., 2020). In a more recent VLSM study, Moore, Gillebert, and Demeyere (2021) suggested that right and left neglect were not anatomically homologous. In this frame, the study of single right-neglect patients cases by using a combined analysis of the grey and white matter could offer additional data to shed some light not only on lesional patterns specific to right neglect after left hemisphere damage, but also more generally on the distribution of attentional networks in the two hemispheres. Consistent with this position, the present study reveals a dissection in vivo of the white matter bundles in three patients with persistent right neglect.

\section{Methods}

\section{Clinical data}

Three patients with a left hemisphere stroke, included in the Centre for Cognitive Anatomy database project (Batrancourt et al., 2002) at the Paris Brain Institute, Pitié Salpêtrière Hospital, were selected for 
the present study. All subjects gave written consent according to the Declaration of Helsinki. The study was approved by the lle-de-France I research ethics committee.

The first patient (P1) was an 81-year-old right-handed man, retired engineer (14 years of schooling) with a prior history of completely recovered left occipital ischemic stroke 3 years before, that resulted in a rightside hemianopia. He came to the emergency ward because of sudden difficulties in using his right superior limb. In the emergency ward, the same day, he was confused, presented facial asymmetry, no coordination in his movements, a right-sided motor deficit, apraxia and astereognosia for the upper right limb. In addition to a right homonymous hemianopia resulting from his occipital stroke, he now showed clinical signs of aphasia, alexia, agraphia, right-side neglect, a right-sided Babinski sign. He remained in the neurological service for one month and then in the rehabilitation unit for two months.

Neuropsychological examinations were realized at one-month post-onset and at the end of the rehabilitation period (three months post-onset). At the end of the rehabilitation period, the patient was well oriented and relatively autonomous in daily life activities, despite a slight motor deficit of the superior right limb and a persistent agraphia. Signs of right neglect were still present.

The second patient (P2) was a 73-year-old right-handed man, retired from work (1 year of schooling). He came to the emergency ward for a sudden right hemiplegia. Global aphasia was reported at the admission. A shunt was applied to treat a hydrocephalus. One month later, the patient presented only signs of impaired comprehension, anomia and signs of right-side neglect. He remained in the neurological unit for one month and then entered in the rehabilitation unit. Neuropsychological examinations were realized at one month and three months after the stroke. At the end of the rehabilitation period, the patient still presented right neglect signs.

The third patient (P3), a 65-year-old right-handed man, retired instructor (5 years of schooling) came to the emergency ward with a sudden right hemiplegia, global aphasia, right hemianopia and signs of rightside neglect. He remained in the neurological service for 3 weeks and was then admitted to rehabilitation for two months. Neuropsychological examinations were realized at one-month post-onset and at the end of the rehabilitation period (three months post-onset). At the end of rehabilitation he had a predominantly expressive aphasia, with slight comprehension difficulties, and right neglect signs.

\section{Neuropsychological assessment}

Visual neglect was assessed by using the GEREN standardized paper-and-pencil battery of tests (Azouvi et al., 2006), including: bells cancellation (Gauthier, Dehaut, \& Joanette, 1989), line bisection (Schenkenberg, Bradford, \& Ajax, 1980), copy of a landscape (Gainotti \& Tiacci, 1971), text reading tests and the Catherine Bergego scale in order to assess patients' behavior in every-day life. We also used line (Albert, 1973) and letter cancellation (Mesulam, 1985) and a different version of the line bisection test (D'Erme, De Bonis, \& Gainotti, 1987).

\section{Neuroimaging data}


MRI scans including high-resolution T1-weighted, T2, T2 FLAIR and diffusion-weighted images were obtained for each patient on a 3T GE scanner with a standard head coil for signal reception 3 months after stroke (4 months for P1). High-resolution T1 3D anatomical SPGR (spoiled gradient recalled) images had the following characteristics: RT [repetition time] = $7164 \mathrm{~ms}$; TE [echo time] = $3124 \mathrm{~ms}$; inversion time $=380 \mathrm{~ms}$; flip angle $=15^{\circ}$; coronal orientation perpendicular to the double echo sequence; acquisition matrix $=[0,288,256$, 0$]$; voxel resolution $=0.5 \times 0.5 \times 1.2 \mathrm{~mm}^{3}$; slice thickness $=1.2 \mathrm{~mm}$; spaces between slices $=1.2 \mathrm{~mm}$.

Brain lesions were segmented on 3D T1 sequences using MRIcron software (https://www.nitrc.org/projects/mricron) and a graphics tablet (WACOM Intuos A6). Images were then normalized to a standard brain template (MNI 152), using Statistical Parametric Mapping 12 running under Matlab. The percentage of lesion on grey matter regions in the left hemisphere was computed by using the AAL template (Tzourio-Mazoyer et al., 2002).

MRI scans equally included a diffusion tensor (DT) sequence, performed using echo-planar imaging with the following parameters: RT (repetition time) $=14 \mathrm{~s}$; TE (echo time) $=75.8 \mathrm{~ms}$; flip angle $=90^{\circ}$; acquisition matrix $=[128,0,0,128]$; percent phase field of view $=100$; slice thickness $=3 \mathrm{~mm}$; voxel resolution $=1,1,3$ $\mathrm{mm}^{3}$; acquisition time $=13 \mathrm{~min}$. Diffusion weighting was performed along 50 independent directions with a b-value of $1000 \mathrm{~s} / \mathrm{mm}^{2}$. The diffusion-weighted data preprocessing was computed using the FSL software (http://www.fmrib.ox.ac.uk/fsl/). During the preprocessing, eddy current-induced distortions were removed and motion distortion corrections were computed; then the estimation of the diffusion tensors was calculated. Using standard computational algorithms, fractional anisotropy (FA), was calculated in the native space. FA threshold was set to 0.2 to exclude most of the voxels with high uncertainty and thus reduce the artifactual reconstruction. The critical angle threshold for stopping tracking in case the algorithm encounters a sharp turn in the fibres direction was fixated at $35^{\circ}$. White matter (WM) tractography was performed using the Trackvis software (http://trackvis.org/dtk). Regions of interest (ROI) were defined in order to be used as the starting points of the tracking process and were manually drawn on axial slices of FA maps on places considered 'obligatory passages' along each white matter tract (Catani, Jones, \& ffytche, 2005; Catani \& Thiebaut de Schotten, 2008; Thiebaut de Schotten et al., 2011). A two ROI approach was used for the intermediate and ventral branches of the superior longitudinal fasciculus (SLF II and III), the inferior fronto-occipital fasciculus (IFOF) and inferior longitudinal fasciculus (ILF) in order to visualise and quantify fibres. All ROls were demarcated on the native space. Resulting tracts were visually inspected to check for aberrant paths.

\section{Results}

\section{Neglect assessment}

Patients' performances on the neglect battery are reported in Table 1. At the first assessment (onemonth post-onset), P1 presented right neglect signs in visual search (bells cancellation), in landscape drawing task, as well as a leftward deviation in the $200 \mathrm{~mm}$ line bisection. At the second evaluation (three 
months post-onset), the patient still presented right neglect on line bisection, visual search, as well as in landscape drawing and text reading, but also in a complementary evaluation including the overlapping figures (one item forgotten to the right). Patient P1 also had right homonymous hemianopia on confrontation.

Patient P2 presented right neglect signs in visual search and landscape drawing at the first assessment (one-month post-onset). When tested at the end of the rehabilitation program (three months post-onset), this patient still presented pathological performances in the visual search. Neglect battery tests did not show any other pathological performance, but this patient had difficulties in real-life situation as assessed by his therapist (Catherine Bergego scale).

Patient P3 presented at one-month post-onset, right neglect signs in visual search and landscape drawing. At the second evaluation (three months post-onset), this patient still presented pathological performance in visual search tests. Patient P3 had right homonymous hemianopia on confrontation.

\section{Table 1}

Table 1. Neuropsychological evaluation of patients. For line bisection, positive values indicate rightward deviations, and negative values indicate leftward deviation. m: months; y: year. *: pathological performance; \#: pathological performance time; --: missing data; NA: not applicable. 


\begin{tabular}{|c|c|c|c|c|c|c|}
\hline \multirow{2}{*}{$\begin{array}{l}\text { Neuropsychological } \\
\text { evaluation }\end{array}$} & \multicolumn{2}{|c|}{ P1 (81-year-old) } & \multicolumn{2}{|c|}{ P2 (73-year-old) } & \multicolumn{2}{|c|}{ P3 (65-year-old) } \\
\hline & $\begin{array}{l}1 \mathrm{~m} \\
\text { post- } \\
\text { onset }\end{array}$ & $\begin{array}{l}3 \mathrm{~m} \\
\text { post- } \\
\text { onset }\end{array}$ & $\begin{array}{l}1 \mathrm{~m} \text { post- } \\
\text { onset }\end{array}$ & $\begin{array}{l}3 \mathrm{~m} \text { post- } \\
\text { onset }\end{array}$ & $\begin{array}{l}1 \mathrm{~m} \text { post- } \\
\text { onset }\end{array}$ & $\begin{array}{l}3 \mathrm{~m} \\
\text { post- } \\
\text { onset }\end{array}$ \\
\hline $\begin{array}{l}\text { Bells cancellation } \\
\text { (L/R hits; } \max 15 / 15 \text { ) }\end{array}$ & $14 / 11$ * & $12 / 10^{*}$ & $13 / 8^{*}$ & 15/14\# & $14 / 11^{\star}$ & $12 / 11^{*}$ \\
\hline $\begin{array}{l}\text { Line cancellation } \\
\text { (L/R hits; } \max 30 / 30)\end{array}$ & $29 / 27$ & $29 / 27$ & - & - & $30 / 30$ & $29 / 30$ \\
\hline $\begin{array}{l}\text { Letter cancellation } \\
\text { (L/R hits; max 30/30) }\end{array}$ & - & $24 / 16^{*}$ & - & $29 / 25^{\star}$ & - & $29 / 28 *$ \\
\hline $\begin{array}{l}\text { Landscape drawing } \\
\text { (R omissions) }\end{array}$ & $1 *$ & $0.5^{\star}$ & $0.5^{\star}$ & 0 & $1 *$ & 0 \\
\hline $\begin{array}{l}\text { Reading (L/R hits; max. } \\
61 / 55)\end{array}$ & $61 / 55$ & $61 / 52^{\star}$ & NA & NA & NA & NA \\
\hline $\begin{array}{l}\text { Line bisection } \\
\text { (\% deviation) }\end{array}$ & - & $-12.71 \% \star$ & $+1.7 \%$ & $-4.7 \%$ & $+0.5 \%$ & $+1.66 \%$ \\
\hline $\begin{array}{l}\text { C. Bergego scale } \\
\text { (real-life situations) }\end{array}$ & - & - & - & $14 / 30 *$ & - & - \\
\hline
\end{tabular}

Lesion segmentation

Lesional patterns are depicted in Figure 1 (see Table 2 for description). For patient P1, the MRI scan documented an old ischemic stroke in the inferior left occipital cortex, affecting both the fusiform and lingual gyri, and a recent left haemorrhagic parietal stroke with moderate perilesional oedema in the region extending from the postcentral gyrus to the temporo-parietal junction (TPJ). This stroke affected the parietal inferior cortex and the white matter lying in its depth, as well as the angular gyrus. There were also signs of leucoaraiosis and cortico-subcortical atrophy.

The patient P2 presented a left parietal haemorrhagic stroke with ventricular inundation as well as right hemisphere micro-bleeds.

The patient P3 presented an ischemic stroke and atrophy at the level of the left precentral and postcentral gyri. Bilateral lacunae in the caudate heads and in corpus callosum were also observed.

Figure 1

Table 2 
Table 2. Percentage of lesion on grey matter regions in the left hemisphere (computations were performed with the AAL template, Tzourio-Mazoyer et al., 2002).

\begin{tabular}{|llll|}
\hline Region & \multicolumn{3}{l}{ \% lesion } \\
& P1 & P2 & P3 \\
\hline Precentral & - & 10 & 5.1 \\
\hline Postcentral & 0.2 & 15 & 29 \\
\hline SupraMarginal & 3.7 & 0.5 & 11 \\
\hline Angular & 22.4 & - & - \\
\hline Parietal Inferior & 18.3 & 1.4 & 4.6 \\
\hline Parietal Superior & 1.4 & - & \\
\hline Paracentral Lobule & - & 9.9 & - \\
\hline Cingular Middle & - & 4.8 & - \\
\hline Lingual & 3.8 & - & - \\
\hline Occipital Inferior & 1.9 & - & - \\
\hline Fusiform & 2.6 & - & - \\
\hline Cerebelum_Crus & 3.3 & - & - \\
\hline Cerebelum & 0.5 & - & - \\
\hline
\end{tabular}

Tractography results

We used DT MRI tractography to dissect in vivo the white matter bundles. Figure 2 and Table 3 present the reconstructed white matter tracts. Reconstructions were made in both hemispheres to compare the FAs for each tract of interest. In the left hemisphere, DT MRI tractography detected disconnections and low FA values in the fronto-parietal networks. On visual inspection, disconnections were also present in the U-shaped fibres linking the superior and inferior frontal gyri. The left IFOF was well represented in all patients, except for patient P1 who had a partial disconnection in its posterior part, lying in the depth of the occipital lobe, where the first stroke had occurred. In P1 there was also evidence of partial damage to the long fibers of the caudal portion of the left ILF, at the level of the lingual gyrus. In the right hemisphere, DTI tractography revealed no disconnection, except for patient P2, who showed low FA values.

Figure 2

Table 3 
Table 3. Values of fractional anisotropy (FA) of white matter bundles reconstructed in each hemisphere. Note the low FA values of the SLF. Maximum damage could be observed in the left SLF. SLF: Superior Longitudinal Fasciculus; IFOF: Inferior Fronto-Occipital Fasciculus; ILF: Inferior Longitudinal Fasciculus; L: left; R: right.

\begin{tabular}{lllllll} 
Patients & SLF R & SLF L & IFOF R & IFOF L & ILF R & ILF L \\
\hline P1 & 0.43 & 0.35 & 0.44 & 0.46 & 0.43 & 0.40 \\
\hline P2 & 0.35 & 0.35 & 0.41 & 0.43 & 0.40 & 0.44 \\
\hline P3 & 0.42 & 0.29 & 0.47 & 0.48 & 0.43 & 0.44
\end{tabular}

\section{Discussion}

In the present study, we report detailed behavioral and anatomical findings in three patients with rightsided neglect after left hemisphere strokes. Two of the patients had predominantly left parietal damage, the third had lesions involving the frontal cortex. Despite this heterogeneity in cortical loci of lesions, white matter tractography demonstrated signs of fronto-parietal SLF disconnection in the left hemisphere of all the patients. This finding suggests an important role of left fronto-parietal dysfunction in right-side neglect, and complements analogous evidence for right SLF II-III disconnection in left neglect (Bartolomeo, Thiebaut de Schotten, \& Chica, 2012; Bartolomeo, Thiebaut de Schotten, \& Doricchi, 2007; Doricchi, Thiebaut de Schotten, Tomaiuolo, \& Bartolomeo, 2008; Migliaccio, Agosta, Scola, et al., 2012; Migliaccio, Agosta, Toba, et al., 2012; Thiebaut de Schotten et al., 2008; Thiebaut de Schotten et al., 2014; Thiebaut de Schotten et al., 2005; Toba, Migliaccio, et al., 2018; Toba et al., 2017; Urbanski et al., 2011).

\section{Behavioural results}

The three patients analysed in the study presented with right neglect signs in paper-and-pencil drawing and visual search tests in the acute stage of the stroke and at three months post onset. After rehabilitation, results obtained by the patients in the same paper-and-pencil tests only slightly changed. Indeed, a systematic study assessing 78 subacute left hemisphere stroke patients (Beis et al., 2004) observed that drawing and visual search tests were the most representative tests to assess right-side neglect (12.8\% of the tested patients presented with neglect signs in bells test and $10.4 \%$ in landscape drawing). However, these tests were also the most representative in the case of left neglect patients, as observed by Azouvi et al. (2002). Moreover, in previous studies, the error patterns of patients after left hemisphere lesions were characterized by (1) target omissions to both left and right sides of the page, (2) fewer omissions of targets overall, comparing with patients with right hemisphere or bilateral lesions and (3) non-significant hemispatial asymmetry (Weintraub et al., 1996). Our patients also subscribed to this general right neglect error pattern, with omissions on both sides of the page in visual search tasks. However, in the landscape copy, two (P2 and P3) out of the three patients perfectly performed this task after rehabilitation. Furthermore, one patient (P1) presented with pathological line bisection that persisted 
also in the second evaluation. Previous studies showed that only $6.4 \%$ of the left brain-damaged patients had signs of neglect in this task (Beis, et al., 2004) and that biased line bisection in long lines (200 mm) was mainly correlated with posterior lesions (retrorolandic cortex, including parietal, but also temporal or occipital regions, or both). These data are in agreement with the lesion localization of our patient. However, an inconsistent pattern of errors in line bisection should be noted for this patient in the second clinical assessment, where we observed deviations towards either the right or the left in the version proposed by D'Erme et al. (1987).

Additionally, only the patient P1 made one right-sided omission in the overlapping figures test in the second evaluation (at three months), this test being perfectly completed at the first evaluation (and perfectly completed by the other patients). Performance of right neglect patients on the overlapping figures test can be variable, being one of the reasons for which right and left neglect are considered as having (at least in part) different natures and underlying mechanisms (Beis et al., 2004; Gainotti, D'Erme, Monteleone, \& Silveri, 1986). The overlapping figures were designed to test the focusing of attention on a relatively small display situated in the central vision. This is in contrast with tests requiring the exploration of larger displays, which are more likely to induce right-sided omissions in left brain-damaged patients (Gainotti et al., 1986). In the original study, when neglect was assessed on the basis of the contralateral extrapersonal space exploration, $41 \%$ of the right and $37 \%$ of the left brain-damaged patients in the explored population had pathological performance. When the capacity to focus attention in the central vision (as assessed with the overlapping figures) was tested, a significant difference was observed, $36 \%$ of the left and only $11 \%$ of the right brain-damaged patients from the same population (Gainotti, et al., 1986) performing pathologically.

\section{Anatomical results}

Results obtained in this study emphasize the role of the left SLF disconnection in right neglect in three patients presenting focal parietal and frontal strokes in the left hemisphere. Early studies on right neglect suggested that it would be preferentially associated with anterior lesions (Ogden, 1985). Beis et al. (2004) found evidence against this hypothesis, because in their sample pathological performance in line bisection, gaze deviation, anosognosia for visual and motor impairment and personal neglect correlated with left posterior lesions (retrorolandic cortex, including parietal, temporal and occipital regions). Other studies considered the possibility that right neglect would be the result of lesions situated in one or more left hemisphere regions, analogous to those areas producing neglect in the right hemisphere and constituting parts of a proposed neuroanatomical network for the spatial distribution of attention (posterior parietal cortex, frontal eye field, cingulate areas, thalamus, caudate, as well as their interconnections) (Mesulam, 1981, 1990). Our results agree with previous studies in confirming this hypothesis (Beume et al., 2017; Beume et al., 2020; Malherbe et al., 2018)see, however (Moore et al., 2021). Generally, severe right neglect was documented to be present in patients with bilateral lesions situated in parietal, occipital and temporal regions, but also in the basal ganglia and the thalamus, the larger of the two lesions being situated in the left hemisphere, posterior to the central sulcus (Bartolomeo et al., 1998; Weintraub et al., 1996). Among the three patients studied here, P2 had low FA values of the 
SLF in both hemispheres, suggesting possible dysfunction of the right hemisphere SLF networks. Patient P3 presented lacunes in the corpus callosum with a possible impact on the transfer of the information relevant for visuospatial attention among the two hemispheres. Inter-hemispheric disconnection, which may play a role in the chronic persistence of left neglect (Bartolomeo, 2019, 2021; Lunven et al., 2019; Lunven et al., 2015), might also contribute to lack of compensation from the healthy hemisphere (Bartolomeo \& Thiebaut de Schotten, 2016) in cases of right-sided neglect. Patient P1 presented corticosubcortical atrophy in both hemispheres, which may also suggest concomitant right hemisphere dysfunction. Further data is needed in order to confirm the hypothesis of the necessity of bilateral lesions in severe right neglect.

\section{Implication for attentional models}

Given that left neglect is more frequent, persistent and severe than right neglect after unilateral lesions, many theories attributed a dominant role to the right hemisphere for the control of spatial distribution of attention (Heilman, Watson, \& Valenstein, 1993; Mesulam, 1999). These models postulate that the right hemisphere directs attention to both ipsilateral and contralateral hemispaces, whereas the left hemisphere is shifting attention only to the right hemispace. Thus, a single lesion in the right hemisphere gives rise to severe neglect because the intact left hemisphere does not have a role in the symmetrical deployment of attention, but only in directing attention to the right. A left hemisphere lesion could produce right neglect, but this would be compensated by the symmetrical distribution of attention controlled by the right hemisphere. Later, Corbetta and Shulman (2002) described (1) an attentional ventral system largely lateralized in the right hemisphere, specialized in the detection of behaviorally relevant stimuli, and (2) an attentional dorsal system distributed bilaterally involved in preparing and applying goal-directed behavior. The two systems are in permanent interaction in normal brains and both would be disturbed in neglect. That is, in these distributed large-scale networks, the left hemisphere correct functioning would also be essential in the deployment of spatial attention. This assumption has also been proposed in one of the earliest models of spatial attention (Kinsbourne, 1977) and confirmed in later studies conducted on left neglect patients (Corbetta, Kincade, Lewis, Snyder, \& Sapir, 2005) that demonstrated during an fMRI paradigm, abnormal activations in structurally intact left hemisphere areas. Thus, the rightward spatial bias of acute neglect patients was associated with hyperactivity in the left dorsal parietal cortex, which normalized in the chronic stage and was accompanied by the behavioral recovery. A support of this model of hemispheric imbalance is given by a previous study (Vuilleumier, Hester, Assal, \& Regli, 1996) that reported spatial neglect (as a result of a right hemisphere stroke) recovery after a second (left hemisphere) stroke (Toba, Godefroy, et al., 2020; Toba, Malherbe, et al., 2020; Toba, Zavaglia, et al., 2020; Valero-Cabré, Toba, Hilgetag, \& Rushmore, 2020). The patients presenting neglect after left hemisphere lesions presented in the current study challenge these models and demonstrate, based on an in vivo reconstruction of white matter bundles, in agreement with functional MRI studies (Corbetta et al., 2005), that left hemisphere also has an important role in the distribution of spatial attention. Alternatively, or in addition, some degree of dysfunction in the right hemisphere SLF III network might be necessary for signs of right-side neglect to emerge (Bartolomeo \& Seidel Malkinson, 2019). 


\section{Conclusion}

In vivo white matter dissection in three patients with right-sided neglect suggests a role for left frontoparietal network disconnection in neglect signs, and complements analogous evidence for right SLF disconnection in left neglect.

\section{Statements And Declarations}

\section{Acknowledgments}

We are thankful to $\mathrm{Dr}$ B. Batrancourt for managing the Centre for Cognitive Anatomy database project. We thank the Naturalia \& Biologia Foundation for providing travel grants for some of the co-authors.

\section{Funding}

The work of Dr Bartolomeo is supported by Agence Nationale de la Recherche through ANR-16-CE37-0005 and ANR-10-IAIHU-06.

\section{Competing interests}

The authors declare they have no relevant financial or non-financial interests to disclose.

\section{Author contributions}

All authors contributed to the study conception and design. Material preparation and data collection were performed by Monica N. Toba. Analyses were performed by Monica N. Toba and Raffaella Migliaccio. The first draft of the manuscript was written by Monica N. Toba and all authors commented on previous versions of the manuscript. All authors read and approved the final manuscript.

\section{Data availability}

Data will be made available on reasonable request.

\section{Ethics approval}

All subjects gave written consent according to the Declaration of Helsinki. The study was approved by the lle-de-France I research ethics committee.

\section{Consent to participate}

Patients consented to participate in the Centre for Cognitive Anatomy database project at the Paris Brain Institute, Pitié Salpêtrière Hospital.

\section{Consent to publish}


Participants provided informed consent in the Centre for Cognitive Anatomy database project.

\section{References}

1. Albert ML (1973) A simple test of visual neglect. Neurology, 23(6), 658-664. Retrieved from https://www.ncbi.nlm.nih.gov/pubmed/4736313

2. Andrade K, Samri D, Sarazin M, de Souza LC, Cohen L, de Schotten M, Bartolomeo P (2010) Visual neglect in posterior cortical atrophy. BMC Neurol, 10, 68. doi:10.1186/1471-2377-10-68

3. Azouvi P, Bartolomeo P, Beis J-M, Perennou D, Pradat-Diehl P, Rousseaux M (2006) A battery of tests for the quantitative assessment of unilateral neglect. Restor Neurol Neurosci 24(4-6):273-285

4. Azouvi P, Samuel C, Louis-Dreyfus A, Bernati T, Bartolomeo P, Beis JM, French Collaborative Study Group on Assessment of Unilateral, N (2002)... .. Sensitivity of clinical and behavioural tests of spatial neglect after right hemisphere stroke. J Neurol Neurosurg Psychiatry, 73(2), 160-166. Retrieved from https://www.ncbi.nlm.nih.gov/pubmed/12122175

5. Bartolomeo P (2019) Visual neglect: getting the hemispheres to talk to each other. Brain 142(4):840842. doi:10.1093/brain/awz043

6. Bartolomeo P (2021) From competition to cooperation: Visual neglect across the hemispheres. Rev Neurol (Paris) 177(9):1104-1111. doi:10.1016/j.neurol.2021.07.015

7. Bartolomeo P, Dalla Barba G, Boisse MF, Bachoud-Levi AC, Degos JD, Boller F (1998) Right-side neglect in Alzheimer's disease. Neurology, 51(4), 1207-1209. Retrieved from https://www.ncbi.nlm.nih.gov/pubmed/9781564

8. Bartolomeo P, Seidel Malkinson T (2019) Hemispheric lateralization of attention processes in the human brain. Curr Opin Psychol 29:90-96. doi:10.1016/j.copsyc.2018.12.023

9. Bartolomeo P, de Thiebaut M (2016) Let thy left brain know what thy right brain doeth: Interhemispheric compensation of functional deficits after brain damage. Neuropsychologia 93(Pt B):407-412. doi:10.1016/j.neuropsychologia.2016.06.016

10. Bartolomeo P, Thiebaut de Schotten M, Chica AB (2012) Brain networks of visuospatial attention and their disruption in visual neglect. Front Hum Neurosci 6:110. doi:10.3389/fnhum.2012.00110

11. Bartolomeo P, Thiebaut de Schotten M, Doricchi F (2007) Left unilateral neglect as a disconnection syndrome. Cereb Cortex, 17(11), 2479-2490. Retrieved from http://www.ncbi.nlm.nih.gov/pubmed/17272263

12. Batrancourt B, Levy R, Lehericy S, Hasboun D, Samson Y, Lavallee I, Dubois B (2002) [An anatomofunctional brain database]. C R Biol 325(4):439-455. doi:10.1016/s1631-0691(02)01444-0

13. Beis JM, Keller C, Morin N, Bartolomeo P, Bernati T, Chokron S, French Collaborative Study Group on Assessment of Unilateral, N (2004)... .. Right spatial neglect after left hemisphere stroke: qualitative and quantitative study. Neurology, 63(9), 1600-1605. Retrieved from https://www.ncbi.nlm.nih.gov/pubmed/15534242 
14. Beume LA, Martin M, Kaller CP, Kloppel S, Schmidt CS, Urbach H, Umarova RM (2017) Visual neglect after left-hemispheric lesions: a voxel-based lesion-symptom mapping study in 121 acute stroke patients. Exp Brain Res 235(1):83-95. doi:10.1007/s00221-016-4771-9

15. Beume LA, Rijntjes M, Dressing A, Kaller CP, Hieber M, Martin M, Weiller C (2020) Dissociation of visual extinction and neglect in the left hemisphere. Cortex 129:211-222. doi:10.1016/j.cortex.2020.04.010

16. Bowen A, McKenna K, Tallis RC (1999) Reasons for variability in the reported rate of occurrence of unilateral spatial neglect after stroke. Stroke, 30(6), 1196-1202. Retrieved from https://www.ncbi.nlm.nih.gov/pubmed/10356099

17. Cambier J, Masson M, Guillot M, Robine B (1985) [Right neglect with hemiasomatognosia, mental confusion, apraxia and agraphia without aphasia]. Rev Neurol (Paris), 141(12), 802-805. Retrieved from https://www.ncbi.nlm.nih.gov/pubmed/3832299

18. Catani M, Jones DK, ffytche DH (2005) Perisylvian language networks of the human brain. Ann Neurol 57(1):8-16. doi:10.1002/ana.20319

19. Catani $M$, de Thiebaut $M$ (2008) A diffusion tensor imaging tractography atlas for virtual in vivo dissections. Cortex 44(8):1105-1132. doi:10.1016/j.cortex.2008.05.004

20. Corbetta M, Kincade MJ, Lewis C, Snyder AZ, Sapir A (2005) Neural basis and recovery of spatial attention deficits in spatial neglect. Nat Neurosci 8(11):1603-1610. doi:10.1038/nn1574

21. Corbetta M, Shulman GL (2002) Control of goal-directed and stimulus-driven attention in the brain. Nat Rev Neurosci 3(3):201-215. doi:10.1038/nrn755

22. D'Erme P, De Bonis C, Gainotti G (1987) Influenza dell'emi-inattenzione e dell'emianopsia sui compiti di bisezione di linee nei pazienti cerebrolesi [Influence of unilateral neglect and hemianopia on line bisection performance in brain-damaged patients]. Archivio di Psicologia Neurologia e Psichiatria 48:165-189

23. Doricchi F, Thiebaut de Schotten M, Tomaiuolo F, Bartolomeo P (2008) White matter (dis)connections and gray matter (dys)functions in visual neglect: gaining insights into the brain networks of spatial awareness. Cortex 44(8):983-995. doi:10.1016/j.cortex.2008.03.006

24. Fischer RS, Alexander MP, Gabriel C, Gould E, Milione J (1991) Reversed lateralization of cognitive functions in right handers. Exceptions to classical aphasiology. Brain, 114 (Pt 1A), 245-261.

Retrieved from https://www.ncbi.nlm.nih.gov/pubmed/1998885

25. Gainotti G, D'Erme P, Bartolomeo P (1991) Early orientation of attention toward the half space ipsilateral to the lesion in patients with unilateral brain damage. J Neurol Neurosurg Psychiatry, 54(12), 1082-1089. Retrieved from https://www.ncbi.nlm.nih.gov/pubmed/1783922

26. Gainotti G, D'Erme P, Monteleone D, Silveri MC (1986) Mechanisms of unilateral spatial neglect in relation to laterality of cerebral lesions. Brain, 109 (Pt 4), 599-612. Retrieved from https://www.ncbi.nlm.nih.gov/pubmed/3730807

27. Gainotti G, Tiacci C (1971) The relationships between disorders of visual perception and unilateral spatial neglect. Neuropsychologia 9:451-458 
28. Gauthier L, Dehaut F, Joanette $Y(1989)$ The bells test: A quantitative and qualitative test for visual neglect. Int J Clin Neuropsychol 11:49-53

29. Heilman KM, Watson RT, Valenstein E (1993) Neglect and related disorders. In: Heilman KM, Valenstein E (eds) Clinical Neuropsychology, 3rd edn. Oxford University Press, New York, pp 279-336

30. Kinsbourne M (1977) Hemi-neglect and hemisphere rivalry. In: Weinstein EA, Friedland RP (eds) Hemi-Inattention and Hemisphere Specialization, vol 18. Raven Press, New York, pp 41-49

31. Lunven M, Rode G, Bourlon C, Duret C, Migliaccio R, Chevrillon E, Bartolomeo P (2019) Anatomical predictors of successful prism adaptation in chronic visual neglect. Cortex 120:629-641. doi:10.1016/j.cortex.2018.12.004

32. Lunven M, De Schotten T, Bourlon M, Duret C, Migliaccio C, Rode R, Bartolomeo P (2015) White matter lesional predictors of chronic visual neglect: a longitudinal study. Brain 138(Pt 3):746-760. doi:10.1093/brain/awu389

33. Malherbe C, Umarova RM, Zavaglia M, Kaller CP, Beume L, Thomalla G, Hilgetag CC (2018) Neural correlates of visuospatial bias in patients with left hemisphere stroke: a causal functional contribution analysis based on game theory. Neuropsychologia 115:142-153. doi:10.1016/j.neuropsychologia.2017.10.013

34. Mark VW, Kooistra CA, Heilman KM (1988) Hemispatial neglect affected by non-neglected stimuli. Neurology, 38(8), 1207-1211. Retrieved from https://www.ncbi.nlm.nih.gov/pubmed/3399068

35. Mesulam MM (1981) A cortical network for directed attention and unilateral neglect. Ann Neurol 10(4):309-325. doi:10.1002/ana.410100402

36. Mesulam MM (1985) Principles of Behavioral Neurology. F.A. Davis, Philadelphia (PA)

37. Mesulam MM (1990) Large-scale neurocognitive networks and distributed processing for attention, language, and memory. Ann Neurol 28(5):597-613. doi:10.1002/ana.410280502

38. Mesulam MM (1999) Spatial attention and neglect: parietal, frontal and cingulate contributions to the mental representation and attentional targeting of salient extrapersonal events. Philos Trans $\mathrm{R}$ Soc Lond B Biol Sci 354(1387):1325-1346. doi:10.1098/rstb.1999.0482

39. Migliaccio R, Agosta F, Scola E, Magnani G, Cappa SF, Pagani E, Filippi M (2012) Ventral and dorsal visual streams in posterior cortical atrophy: a DT MRI study. Neurobiol Aging 33(11):2572-2584. doi:10.1016/j.neurobiolaging.2011.12.025

40. Migliaccio R, Agosta F, Toba MN, Samri D, Corlier F, de Souza LC, Bartolomeo P (2012) Brain networks in posterior cortical atrophy: a single case tractography study and literature review. Cortex 48(10):1298-1309. doi:10.1016/j.cortex.2011.10.002

41. Moore MJ, Gillebert CR, Demeyere N (2021) Right and left neglect are not anatomically homologous: A voxel-lesion symptom mapping study. Neuropsychologia 162:108024. doi:10.1016/j.neuropsychologia.2021.108024

42. Ogden JA (1985) Anterior-posterior interhemispheric differences in the loci of lesions producing visual hemineglect. Brain Cogn, 4(1), 59-75. Retrieved from https://www.ncbi.nlm.nih.gov/pubmed/4027055 
43. Posner MI, Walker JA, Friedrich FJ, Rafal RD (1984) Effects of parietal injury on covert orienting of attention. J Neurosci 4:1863-1874

44. Rastelli F, Funes MJ, Lupiáñez J, Duret C, Bartolomeo P (2008) Left neglect: Is the disengage deficit space- or object-based? Exp Brain Res 187(3):439-446

45. Schenkenberg T, Bradford DC, Ajax ET (1980) Line bisection and unilateral visual neglect in patients with neurologic impairment. Neurology, 30(5), 509-517. Retrieved from

https://www.ncbi.nlm.nih.gov/pubmed/7189256

46. Stone SP, Patel P, Greenwood RJ, Halligan PW (1992) Measuring visual neglect in acute stroke and predicting its recovery: the visual neglect recovery index. J Neurol Neurosurg Psychiatry, 55(6), 431436. Retrieved from https://www.ncbi.nlm.nih.gov/pubmed/1619406

47. Stone SP, Wilson B, Wroot A, Halligan PW, Lange LS, Marshall JC, Greenwood RJ (1991) The assessment of visuo-spatial neglect after acute stroke. J Neurol Neurosurg Psychiatry, 54(4), 345350. Retrieved from https://www.ncbi.nlm.nih.gov/pubmed/2056321

48. Thiebaut de Schotten M, Dell'Acqua F, Forkel SJ, Simmons A, Vergani F, Murphy DG, Catani M (2011) A lateralized brain network for visuospatial attention. Nat Neurosci 14(10):1245-1246. doi:10.1038/nn.2905

49. Thiebaut de Schotten M, Kinkingnehun S, Delmaire C, Lehericy S, Duffau H, Thivard L, Bartolomeo P (2008) Visualization of disconnection syndromes in humans. Cortex 44(8):1097-1103. doi:10.1016/j.cortex.2008.02.003

50. Thiebaut de Schotten M, Tomaiuolo F, Aiello M, Merola S, Silvetti M, Lecce F, Doricchi F (2014) Damage to white matter pathways in subacute and chronic spatial neglect: a group study and 2 single-case studies with complete virtual "in vivo" tractography dissection. Cereb Cortex 24(3):691706. doi:10.1093/cercor/bhs351

51. Thiebaut de Schotten M, Urbanski M, Duffau H, Volle E, Levy R, Dubois B, Bartolomeo P (2005) Direct evidence for a parietal-frontal pathway subserving spatial awareness in humans. Science 309(5744):2226-2228. doi:10.1126/science.1116251

52. Toba MN, Godefroy O, Rushmore RJ, Zavaglia M, Maatoug R, Hilgetag CC, Valero-Cabré A (2020) Revisiting 'brain modes' in a new computational era: approaches for the characterization of brainbehavioural associations. Brain 143(4):1088-1098. doi:10.1093/brain/awz343

53. Toba MN, Malherbe C, Godefroy O, Rushmore RJ, Zavaglia M, Maatoug R, Hilgetag CC (2020) Reply: Inhibition between human brain areas or methodological artefact? Brain 143(5):e39. doi:10.1093/brain/awaa093

54. Toba MN, Migliaccio R, Batrancourt B, Bourlon C, Duret C, Pradat-Diehl P, Bartolomeo P (2018) Common brain networks for distinct deficits in visual neglect. A combined structural and tractography MRI approach. Neuropsychologia 115:167-178. doi:10.1016/j.neuropsychologia.2017.10.018

55. Toba MN, Rabuffetti M, Duret C, Pradat-Diehl P, Gainotti G, Bartolomeo P (2018) Component deficits of visual neglect: "Magnetic" attraction of attention vs. impaired spatial working memory. 
Neuropsychologia 109:52-62. doi:10.1016/j.neuropsychologia.2017.11.034

56. Toba MN, Zavaglia M, Malherbe C, Moreau T, Rastelli F, Kaglik A, Valero-Cabré A (2020) Game theoretical mapping of white matter contributions to visuospatial attention in stroke patients with hemineglect. Hum Brain Mapp 41(11):2926-2950. doi:10.1002/hbm.24987

57. Toba MN, Zavaglia M, Rastelli F, Valabregue R, Pradat-Diehl P, Valero-Cabre A, Hilgetag CC (2017) Game theoretical mapping of causal interactions underlying visuo-spatial attention in the human brain based on stroke lesions. Hum Brain Mapp. doi:10.1002/hbm.23601

58. Tzourio-Mazoyer N, Landeau B, Papathanassiou D, Crivello F, Etard O, Delcroix N, Joliot M (2002) Automated anatomical labeling of activations in SPM using a macroscopic anatomical parcellation of the MNI MRI single-subject brain. Neurolmage 15(1):273-289. doi:10.1006/nimg.2001.0978

59. Urbanski M, Thiebaut de Schotten M, Rodrigo S, Oppenheim C, Touze E, Meder JF, Bartolomeo P (2011) DTI-MR tractography of white matter damage in stroke patients with neglect. Exp Brain Res 208(4):491-505. doi:10.1007/s00221-010-2496-8

60. Valero-Cabré A, Toba MN, Hilgetag CC, Rushmore RJ (2020) Perturbation-driven paradoxical facilitation of visuo-spatial function: Revisiting the 'Sprague effect'. Cortex. Retrieved from https://www.sciencedirect.com/science/article/pii/S0010945219300516

61. Vuilleumier P, Hester D, Assal G, Regli F (1996) Unilateral spatial neglect recovery after sequential strokes. Neurology, 46(1), 184-189. Retrieved from https://www.ncbi.nlm.nih.gov/pubmed/8559371

62. Weintraub S, Daffner KR, Ahern GL, Price BH, Mesulam MM (1996) Right sided hemispatial neglect and bilateral cerebral lesions. J Neurol Neurosurg Psychiatry, 60(3), 342-344. Retrieved from https://www.ncbi.nlm.nih.gov/pubmed/8609518

\section{Figures}

\section{Figure 1}

T1 MRI scans of the three patients in the native space. 


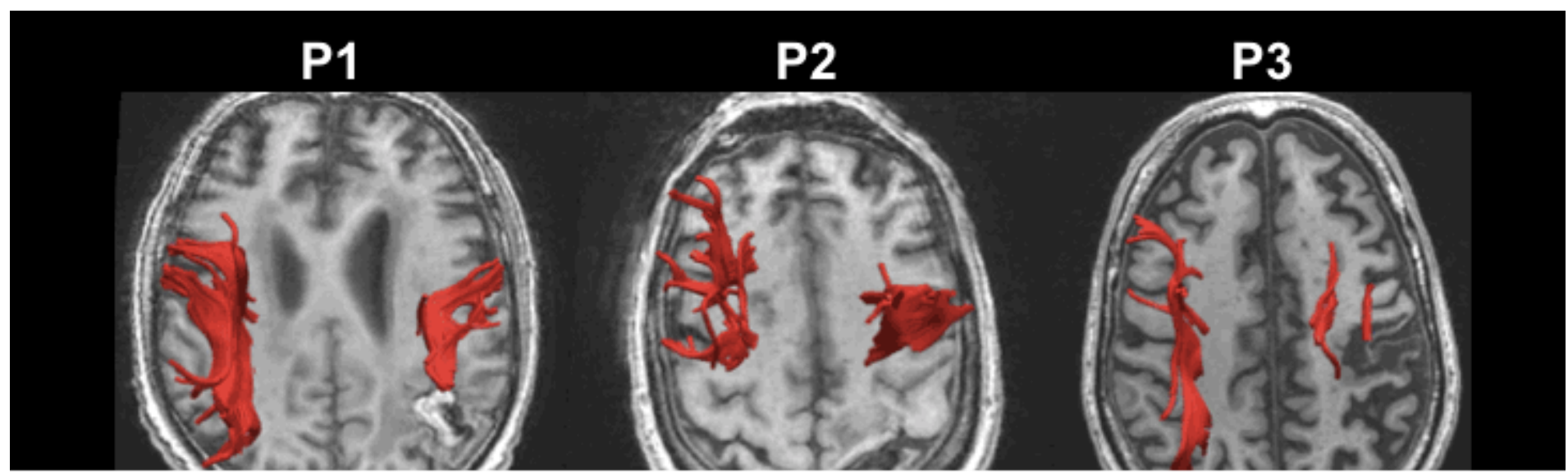

Figure 2

Reconstructions in native space of the principal tracts of interest in the left $(\mathrm{L})$ hemisphere and in the right $(R)$ hemisphere. Note the loss of fibers in left hemisphere SLF in all the patients, as well as the caudal loss of fibres in the IFOF and ILF bundles in P1. Red: Superior longitudinal fasciculus; Green: Inferior fronto-occipital fasciculus; Blue: Inferior longitudinal fasciculus; R: right; L: left. 